\title{
CORRELATION OF ETYMOLOGICAL MEANING OF THE CONCEPT "URGENCY" AS THE PERSONIFICATION OF THE EVALUATIVE CATEGORY, WITH THE LEGAL NATURE OF THE INSTITUTION OF URGENT INVESTIGATIVE ACTIONS
}

\author{
Stanislav N. Kabelkov \\ Volgograd State University, Volgograd, Russian Federation
}

Guram L. Grigolia

Krasnodar University of the Russian Interior Ministry, Krasnodar, Russian Federation

\begin{abstract}
Introduction: the inability to avoid the use by the legislator of the evaluative categories in the framework of criminal procedure law raises questions about their precise and uniform understanding for the purpose of execution of the provisions contained in the norms of the current Criminal Procedure Code of the Russian Federation (further, unless otherwise specified, UPK). In this regard, the attention is drawn to the institution of urgent investigative actions, in whose name the legislator has put the evaluative concept of "urgency". The attention is drawn to some etymological discrepancy between the name and the possibilities of law enforcement in the implementation of the norms of the institution of urgent investigative actions. Purpose: to conduct a study of the evaluative category "urgency" used in criminal procedure law for correlation with the institution of urgent investigative actions. Methods: the authors use the following methods of scientific knowledge: the general scientific methods (analysis, synthesis, induction, deduction) and the system-structural one, which allows analyzing the development of the institution of urgent investigative actions. Results: the study found that in the current criminal procedure legislation in order to delineate the boundaries of a separate group of investigative actions the evaluative category "urgency" is used. However, the content of the articles of criminal procedure law, regulating their practical application, does not allow us to make a complete picture of the legal nature of an independent legal institution, which is the institution of "urgent investigative actions". Conclusions: as a result of the study it is found that the procedural capabilities of the institution of urgent investigative actions, presented in the current UPK, from the standpoint of the etymological approach correspond to a greater extent to the term "immediateness" than urgency. In this regard, it seems possible to conduct research on the establishment in the system of investigative actions the independent criminal procedural institutions of "immediate investigative actions" and "urgent investigative actions" with the mandatory theoretical developments that allow defining clear criteria for the application of the above evaluative concepts.
\end{abstract}

Key words: urgent investigative actions, bodies of preliminary investigation, bodies of inquiry, investigative actions, evaluative concepts (categories) of criminal procedure.

Citation. Kabelkov S.N., Grigolia G.L. Correlation of Etymological Meaning of the Concept "Urgency" as the a Personification of the Evaluative Category, with the Legal Nature of the Institution of Urgent Investigative Actions. Legal Concept, 2019, vol. 18, no. 2, pp. 49-54. (in Russian). DOI: https://doi.org/10.15688/lc.jvolsu.2019.2.7

\section{КОРРЕЛЯЦИЯ ЭТИМОЛОГИЧЕСКОГО СОДЕРЖАНИЯ ПОНЯТИЯ «НЕОТЛОЖНОСТИ» КАК ПЕРСОНИФИКАЦИИ ОЦЕНОЧНОЙ КАТЕГОРИИ С ЮРИДИЧЕСКОЙ ПРИРОДОЙ ИНСТИТУТА НЕОТЛОЖНЫХ СЛЕДСТВЕННЫХ ДЕЙСТВИЙ}

\section{Станислав Николаевич Кабельков}

Волгоградский государственный университет, г. Волгоград, Российская Федерация 


\section{Гурам Львович Григолия}

Краснодарский университет МВД России, г. Краснодар, Российская Федерация

Введение: невозможность избежать использования законодателем оценочных категорий в рамках уголовно-процессуального права порождает вопросы об их точном и единообразном понимании с целью исполнения предписаний, содержащихся в нормах действующего Уголовно-процессуального кодекса Российской Федерации (далее, если не оговорено иное, - УПК). В этой связи обращает на себя внимание институт неотложных следственных действий, в название которого законодатель вложил оценочное понятие «неотложности». Обращает на себя внимание некоторое этимологического несоответствие между наименованием и возможностями правоприменителя при реализации норм института неотложных следственных действий. Цель: провести исследование используемой в уголовно-процессуальном праве оценочной категории «неотложность» на предмет корреляции с институтом неотложных следственных действий. Методы: авторами используются следующие методы научного познания: общенаучные (анализ, синтез, индукция, дедукция), системно-структурный, позволивший проанализировать построение института неотложных следственных действий. Результаты: в ходе исследования установлено, что в действующем уголовно-процессуальном законодательстве для того, чтобы очертить границы отдельной группы следственных действий, используется оценочная категория «неотложность». Однако содержание статей уголовно-процессуального закона, регламентирующих их практическое применение, не позволяет составить целостную картину юридической природы самостоятельного правового института, которым является институт «неотложных следственных действий». Выводы: в результате проведенного исследования установлено, что процессуальные возможности института неотложных следственных действий, представленного в действующем УПК, в большей степени, с позиции этимологического подхода, соответствуют термину «безотлагательность», чем «неотложность». В этой связи видится возможным провести исследование на предмет создания в системе следственных действий самостоятельных уголовно-процессуальных институтов «безотлагательных следственных действий» и «неотложных следственных действий» при обязательных теоретических разработках, позволяющих определить четкие критерии применения вышеуказанных оценочных понятий.

Ключевые слова: неотложные следственные действия, органы предварительного расследования, органы дознания, следственные действия, оценочные понятия (категории) уголовного судопроизводства.

Цитирование. Кабельков С. Н., Григолия Г. Л. Корреляция этимологического содержания понятия «неотложности» как персонификации оценочной категории с юридической природой института неотложных следственных действий // Legal Concept = Правовая парадигма. - 2019. - Т. 18, № 2. - C. 49-54. - DOI: https:// doi.org/10.15688/lc.jvolsu.2019.2.7

\section{Введение}

Приступая к исследованию значения оценочных категорий, будет вполне уместным вспомнить о праве как о некой системе, позволяющей эффективно регламентировать и регулировать общественные отношения, а именно о незыблемом свойстве так называемого континентального права - возможности регулировать общественные отношения не только по «букве», но и по «духу закона».

Действительно, при конструировании правовой нормы невозможно просчитать все возможные ситуации, которые могут возникнуть при ее реализации. Поэтому основным критерием эффективности правовой нормы должна выступать следующая концепция: регулируемые общественные отношения должны соответствовать «духу закона». Отсюда следует, что некие частности или конкретные жизнен- ные ситуации не могут выходить за пределы правового регулирования. Позволим себе предположить, что отечественный законодатель сознательно, умышленно и постепенно внедряет в структуру права оценочные понятия, для того чтобы правоприменитель обладал возможностью не только буквального, но и расширительного толкования правовых норм с целью расширения границ их применения и повышения социальной эффективности.

\section{Оценочные категории и уголовное судопроизводство}

Оценочные понятия, именуемые также в литературе правовыми категориями, представляют собой довольно сложное правовое явление, присущее уголовному судопроизводству. Однако исследуются они с относительно недавнего времени и выступают в каче- 
стве предмета научных исследований с начала второй половины XX века [2, с. 14]. Следует признать, что до настоящего времени вопросы об их месте в уголовно-процессуальном праве, а также о выполняемых функциях в реализации уголовно-процессуальных норм продолжают оставаться традиционно-дискуссионными [6, с. 143].

Ряд выдающихся ученых высказались о роли и месте оценочных понятий в отечественной правовой системе. Так, С.С. Алексеев полагал, что оценочные понятия «ориентированы на то, чтобы... правоприменитель... конкретно, с учетом особенностей той или иной ситуации оценил фактическую обстановку и конкретизировал общую формулу закона», что «они позволяют правоприменителю действовать с учетом условий, места и времени» [1, с. 105]. Поэтому следует принять позицию В.Н. Кудрявцева, утверждающего, что «существование оценочных понятий в законе неизбежно» [4, с. 138].

Констатация данного факта способствовала возникновению среди ученых-юристов дискуссии о месте оценочных понятий в системе отечественного права. Некоторые авторы предприняли попытку рассмотреть их юридическую природу при помощи категорий морального сознания, имеющих субстанциональную природу, таких как «благо» или «зло». Между тем, отходя от некой эмфатичности, которую допускают авторы, пытающиеся найти место оценочных категорий в системе права, все же следует признать факт влияния оценочных понятий не только на толкование уголовно-процессуальных норм, но и на правоприменительную практику.

Использование оценочных категорий в уголовном судопроизводстве имеет некоторые специфические особенности. В первую очередь это обусловлено тем, что применение норм уголовно-процессуального права позволяет не только вторгнуться в саму систему, но и до определенной степени - в механизм конституционных правовых гарантий. Не может остаться незамеченным предоставление в распоряжение органов дознания и предварительного следствия норм, регламентирующих применение принуждения. Поэтому к оценочным категориям в рамках уголовного судопроизводства необходимо подходить наиболее деликатно.
С целью уяснения функции оценочных категорий в институте неотложных следственных действий возникает необходимость в проведении исследования относительно их правовой полезности и возможности разрешить некоторые проблемы, которые не могут быть устранены в результате использования иного правового инструментария.

Исследования, проводимые в данной области в юридической литературе, позволили сформулировать категории, принадлежащие к числу оценочных. Критериями, избранными в основу проводимой классификации, выступили: основания и условия принятия процессуальных решений, правила оценки доказательств.

Нисколько не умаляя значения целого ряда институтов уголовного судопроизводства, использующих оценочные понятия, невозможно не обратить внимания на институт неотложных следственных действий [3, с. 93], название которого исходит из оценочного понятия.

\section{Оценочная категория «неотложности» в институте неотложных следственных действий}

Среди предлагаемых в юридической литературе разграничений различных видов следственных действий в качестве основания, позволяющего определить неотложные следственные действия в самостоятельную подсистему, называют желание законодателя. Представляется, что с позиции формальной логики это не вполне корректно, поскольку при определении неотложных следственных действий в отдельную группу путем мерологического деления не соблюдаются правила ни дихотомии, ни таксономии. Однако соблюдение предписаний закона требует не только признать факт их существования, но и эффективного средства доказывания. Данный правовой инструментарий с позиции законодателя необходим для того, чтобы органы дознания имели возможность начать расследование.

Естественно, первое, что вызывает интерес, - это этимология термина «неотложность», поскольку выступает в уголовном судопроизводстве в качестве оценочной категории. Его толкование напрямую зависит от возможности правоприменителя осуществить свою деятельность в рамках закона, а также 
в интересах участников уголовного процесса. Вероятно, поэтому законодатель ввел «неотложность» в содержание целого ряда статей действующего уголовно-процессуального законодательства (п. 19 ст. 5; п. 2 ч. 2 ст. 40; п. 1 ч. 1 ст. 40.1 ; п. 1 ч. 1 ст. 40.2 ; ч. 2.1 ст. 82 ; ч. 3 ст. 149; ч. 5 ст. 152 УПК РФ).

Примечательно, что законодатель не определил легальные признаки «неотложности», но обозначил цель, для достижения которой проводятся неотложные следственные действия - «обнаружение и фиксация следов преступления; доказательств, требующих незамедлительного закрепления, изъятия и исследования», а также определил круг субъектов, наделенных правом их производства ${ }^{1}$. Аналогичные положения содержались и в УПК РСФСР - «установление и закрепление следов преступления» ${ }^{2}$.

Этимологический подход может навести на мысль о том, что неотложные - это некие особенные следственные действия, имеющие специфические признаки, влияющие на юридические и фактические основания их производства.

В словарях толкования слов русского языка термин «неотложность» понимается как безотлагательность, срочность, спешность, экстренность, незамедлительнось; первоочередность, неотлагательность, безотложность; выполнение которого нельзя отложить; недопускающий промедления; срочный [5].

Представляется ситуация, когда уже на стадии возбуждения уголовного дела или сразу после этого должностное лицо, представляющее орган предварительного расследования, может прибегнуть к производству следственных действий, позволяющих обнаружить, закрепить, изъять следы преступления.

Буквальное толкование права, а в нашем случае использование термина «неотложность», позволяет предположить, что органы предварительного расследования обладают неким правовым инструментарием, позволяющим быстро, эффективно, экстренно и без промедления раскрыть преступления и установить виновных лиц. Но законодатель как в УПК РСФСР, так и в УПК РФ предлагает иную юридическую природу «неотложности» применительно к следственным действиям, в качестве отличительного признака указывая на предоставление органу дознания возможности приступить к процессу доказывания.

Понимание неотложных следственных действий законодатель ограничил процессуальным реагированием органа дознания на преступление, требующего предварительного расследования в форме следствия. Следует признать такое понимание анализируемого института крайне узким, не затрагивающим многие существенные основания.

Можно предположить, что, наделяя орган дознания правом возбуждать уголовные дела о преступлениях, по которым обязательно нужно производить предварительное следствие и производить неотложные следственные действия, законодатель руководствовался тем, что орган дознания в большинстве случаев первый обнаруживает признаки таких преступлений и имеет все возможности выявить и зафиксировать следы, имеющие доказательственную информацию. Считаем такое предположение спорным, ведь в следственной практике случаи, когда признаки преступления, по которому обязательно нужно производить предварительное следствие, обнаруживаются не органом дознания, а следователем, не редкость. Следует ли отсюда, что в данном случае институт производства неотложных следственных действий следователем должен быть применен по аналогии? Подобное высказывание ведет к спорам, вызванным нормой УПК РФ, устанавливающей запрет для следователя возбуждать уголовное дело, ему не подследственное, а значит и запрет на производство неотложных следственных действий. Буквальное толкование ч. 1 ст. 157 УПК РФ позволяет делать вывод, что в такой ситуации следователь лишь уведомляет орган дознания, в компетенцию которого входит и решение вопроса о возбуждении уголовного дела и производстве неотложных следственных действий. Если принятие решения затягивается, это может способствовать утрате доказательственной информации и затруднит последующее расследование. Факт установления 10 суток для производства неотложных следственных действий не случаен. В этом и отражен первостепенный смысл неотложных следственных действий, которые должны быть произведены безотлагательно.

Полагаем, что если уголовное дело возбудит не орган дознания, а следователь, кото- 
С.Н. Кабельков, Г.Л. Григолия. Корреляция этимологического содержания понятия «неотложности»

рому уголовное дело не подследственно, и произведет при этом неотложные следственные действия, доказательства, полученные по такому делу, должны быть признаны недопустимыми, полученными с нарушением требований УПК РФ, устанавливающих правила подследственности.

\section{Выводы}

На основании вышеизложенного представляется возможным резюмировать ответ на вопрос о соответствии категории «неотложности» применительно соотношения этимологического содержания и юридической природы неотложных следственных действий.

Представляется, что процессуальные возможности института неотложных следственных действий, представленного в действующем УПК, в большей степени, с позиции этимологического подхода, соответствуют термину «безотлагательность», чем неотложность. В этой связи видится возможным провести исследования на предмет создания в системе следственных действий самостоятельных уголовно-процессуальных институтов «безотлагательных следственных действий» и «неотложных следственных действий» при обязательных теоретических разработках, позволяющих определить четкие критерии применения вышеуказанных оценочных понятий.

Кроме того, анализ современного состояния института неотложных следственных действий указывает на неразрешенности целого ряда вопросов: о месте и роли неотложных следственных действий в системе следственных действий, а также в системе доказательственного права; о необходимости определения субъекта, который определяет степень «неотложности»; о допустимых границах «неотложности»; о соответствии категории «неотложности» «букве» и «духу» уголовнопроцессуального права и, самое главное, правовым возможностям по обеспечению процессуальных гарантий участников уголовного судопроизводства, реализации их прав и свобод.

\section{ПРИМЕЧАНИЯ}

1 Уголовно-процессуальный кодекс Российской Федерации от 18.12.2001 № 174-Ф3 (ред. от
06.03.2019). URL: http://www.consultant.ru (дата обращения: 26.03.2019).

2 Уголовно-процессуальный кодекс РСФСР (утв. ВС РСФСР 27.10.1960). URL: http://www. consultant.ru (дата обращения: 26.03.2019).

\section{СПИСОК ЛИТЕРАТУРЫ}

1. Алексеев, С. С. Право: азбука - теория философия: опыт комплексного исследования / С. С. Алексеев. - М. : Норма, 1999. - 712 с.

2. Вильнянский, С. И. Применение норм советского права / С. И. Вильнянский // Ученые записки Харьковского юридического института. Вып. 7. - Харьков, 1956. - 172 с.

3. Кругликов, А. П. Неотложные следственные действия / А. П. Кругликов // Уголовное право. - 2004. - № 3. - С. 93-94.

4. Кудрявцев, В. Н. Теоретические основы квалификации преступлений / В. Н. Кудрявцев. - М. : Госюриздат, 1963. - 324 с.

5. Ожегов, С. И. Толковый словарь русского языка / С. И. Ожегов ; под ред. проф. Л. И. Скворцова. 28-е изд., перераб. - М. : Мир и образование, 2014. 1376 с. - Электрон. текстовые дан. - Режим доступа: http://slovariki.org (дата обращения: 20.03.2019).

6. Соловьева, Н. А. Значение дифференциации оценочного терминологического аппарата для модернизации уголовно-процессуальной деятельности / Н. А. Соловьева // Вестник Волгоградского государственного университета. Серия 5, Юриспруденция. - 2013. - № 2 (19). - С. 143-150.

\section{REFERENCES}

1. Alekseev S.S. Law: ABC - Theory Philosophy: Experience of Complex Research. Moscow, Norma Publ., 1999. 712 p. (in Russian).

2. Vilnyanskiy S.I. Application of Norms of the Soviet Right. Scientific Notes of the Kharkov Legal Institute. Iss. 7. Kharkov, 1956. 172 p. (in Russian).

3. Kruglikov A.P. Urgent Investigative Actions. Criminal Law, 2004, no. 3, pp. 93-94.

4. Kudryavtsev V.N. Theoretical Bases of Qualification of Crimes. Moscow, Gosyurizdat, 1963. 324 p. (in Russian).

5. Ozhegov S.I. Dictionary of Russian Language. Moscow, Peace and education Publ., 2014. 1376 p. URL: http://slovariki.org (accessed 20 March 2019). (in Russian).

6. Solovyova N.A. The Value of Differentiation of the Evaluative Terminological Apparatus for the Modernization of Criminal Procedure. Science Journal of Volgograd State University. Jurisprudence, 2013, no. 2 (19), pp. 143-150. (in Russian). 


\section{Information about the Authors}

Stanislav N. Kabelkov, Candidate of Sciences (Jurisprudence), Associate Professor, Department of Criminal Procedure and Criminology, Volgograd State University, Prosp. Universitetsky, 100, 400062 Volgograd, Russian Federation, Kabelkov_stas@mail.ru, https://orcid.org/0000-0002-1760-2281

Guram L. Grigolia, Junior Scientific Assistant, Department of Criminal Procedure, Krasnodar University of the Russian Interior Ministry, Yaroslavskaya St., 128, 350005 Krasnodar, Russian Federation, guram770@gmail.com, https://orcid.org/0000-0002-3158-0998

\section{Информация об авторах}

Станислав Николаевич Кабельков, кандидат юридических наук, доцент кафедры уголовного процесса и криминалистики, Волгоградский государственный университет, просп. Университетский, 100, 400062 г. Волгоград, Российская Федерация, Kabelkov_stas@mail.ru, https:// orcid.org/0000-0002-1760-2281

Гурам Львович Григолия, адъюнкт кафедры уголовного процесса, Краснодарский университет МВД России, ул. Ярославская, 128, 350005 г. Краснодар, Российская Федерация, guram770@gmail.com, https://orcid.org/0000-0002-3158-0998 